\title{
Undrained Dynamic Behavior of Reinforced Subgrade under Long-Term Cyclic Loading
}

\author{
Min Geng $\mathbb{D}^{1,2}$ Debin Wang, ${ }^{2}$ and Peiyong $\mathrm{Li}^{2}$ \\ ${ }^{1}$ Institute of Geotechnical Engineering, Dalian University of Technology, Dalian 116024, China \\ ${ }^{2}$ School of Civil Engineering, Dalian JiaoTong University, Dalian 116028, China \\ Correspondence should be addressed to Min Geng; gengmin@dlut.edu.cn
}

Received 26 December 2017; Revised 1 September 2018; Accepted 12 September 2018; Published 23 October 2018

Guest Editor: Rujie He

Copyright (c) 2018 Min Geng et al. This is an open access article distributed under the Creative Commons Attribution License, which permits unrestricted use, distribution, and reproduction in any medium, provided the original work is properly cited.

To study the dynamic behavior of reinforced subgrade, a series of undrained cyclic triaxial tests of reinforced soil (the specimen a height of $50 \mathrm{~cm}$ and a diameter of $20 \mathrm{~cm}$ ) were performed in this paper. The specimens were tested by varying confining pressure, vibration frequency, dynamic stress amplitudes, and reinforced layers. Orthogonal experiment is a better way to optimize the process of experiment. Impact on dynamic behavior of the reinforced soil specimens is discussed through orthogonal design of experiments in four factors and three levels. This study has demonstrated that the order of dynamic elastic modulus of reinforced soil is influenced by dynamic stress amplitude, frequency, reinforced layer, and confining pressure within changing in factor level. The dynamic stress amplitude has great influence on the dynamic elastic modulus of reinforced soil. The bearing capacity and dynamic elastic modulus of reinforced subgrade decrease slightly with the increase of dynamic strain. Frequency has an influence on the dynamic elastic modulus. It is shown that the cumulative strain of reinforced soil is related to the vibration frequency. The test results also exemplify the reinforced subgrade restrict lateral displacement of subgrade and reduce settlement of subgrade under long-term cyclic loading.

\section{Introduction}

In recent years, high-speed railway and heavy-haul railway have become a major tendency for the development of modern railway in China. Reinforcement is an effective and reliable technique for increasing the strength and stability of subgrade soil. This technique is used in a variety of applications ranging from retaining walls to subgrade and so on. Geogrid is a type of synthetic materials being used to improve engineering properties of soil by providing extra resistance of shear and tensile stress. The dynamic effect of train and railway track has been significantly enhanced by the acceleration of train speed and the increase of axle weight. On one hand, the vibration of the track increases under the cyclic loading, which accelerates the break of the railway track. On the other hand, the railway subgrade is composed of loose soil material with obvious anisotropy, which appears to be characterized by nonlinearity, hysteresis, and deformation accumulation. Unlike the earthquake or storm wave loading, low amplitude one-way cyclic loading is more typical for traffic loading. Reinforced subgrade is subjected to large numbers of load applications at a stress level below their strength.

After years of railway operation, uneven settlement of the subgrade has been observed, and then the deformation accelerates, which aggravates the interaction between the railway track and the train. It can cause significant problems in railway infrastructure and is a challenge for the engineers to keep railway track working well. Therefore, it is of great practical relevance to study the dynamic behavior of reinforced subgrade under traffic loading. At present, the methods used to study the dynamic behavior of soil are divided into experimental study (field test and model test) and theoretical study (analytical method and numerical simulation).

In the past decades, many experimental studies have been carried out to investigate the dynamic behavior under longterm cyclic loading. For example, cyclic triaxial tests, resonant column tests, and shaking table tests on the dynamic behavior of reinforced soil were reported earlier by $[1,2,3,4,5]$. 
The vertical acceleration, horizontal acceleration, and vertical displacement of reinforced retaining walls increase gradually as the height of the wall grows [6]. However, the tendency of increasing of horizontal displacement is not obvious, which has a strong relation with stress waveform generated by train loads. Model tests on the reinforced retaining wall under the repeated loads were carried out to investigate the dynamic response of the retaining wall [7]. It is shown that the displacement average value of the wall is related to the height of the wall. With the increase of dynamic load, the tendency of displacement and strength of reinforced retaining wall go through three stages: vibration compaction stage, vibration shear stage, and vibration failure stage.

In addition, the residual volumetric strain and shear deformations are reduced by the reinforcement, and the model parameters become smaller [8]. With the increase of deviator stress ratio at high confining pressure, the shear modulus decreases. The rate of loss of shear modulus is found to be much lower for fiber-reinforced specimens [9]. Elastic modulus of fiber-reinforced soil increases with increase of fiber content and confining pressure and decreases with increase of loading repetition [10]. The dynamic behavior of the mixture is significantly affected by the content of injected foam and also confining stresses [11]. Stress conditions with selected levels of low confining pressure were used to simulate specific conditions. Particular attention was paid to the bedding error at the top and the bottom ends of the specimens and to fix transducers onto the membrane to be used under low confining pressure [12].

A large-scale model test of reinforced gabion walls was performed with different input sine wave frequencies and amplitudes [13]. It was found that the inside and the outside of reinforced gabion walls under loads (imposed two million times) do not show significant local and overall damage, when the vibration frequency reaches $10 \mathrm{~Hz}$. But, there are great changes of vertical and horizontal acceleration and displacement response of the reinforced gabion wall. The ratio of the elasticity modulus of the material after saturation to its elasticity modulus in dry condition and the saturation induced sudden volumetric strain decrease as the confining pressure increases [14]. The decay of $G / G_{0}$ observed in TS$\mathrm{RC}$ tests starts at a lower strain level and is more evident, especially at high strain level and low confinement stress [15]. The dynamic deformation characteristics of the reinforced sand are defined in terms of wall lateral deformation and rotation. The results indicate the effectiveness of fiber reinforcement in improving dynamic properties of fine sand and deformation characteristics of fiber-reinforced sheet pile retaining wall during shaking [16]. Besides, a great number of researchers have conducted analysis for simulating the dynamic response of reinforced subgrade by establishing track-subgrade numerical models.

The dynamic elastic modulus and damping ratio are two of the most important indicators for design and calculation analysis of reinforced soil structure. In the present research, most analysis and calculation of the geotechnical engineering are inseparable from the two indicators, which are affected by many factors. However, previous studies have mostly focused on the silty clay, silty soil, and soft clay. No comprehensive study has been reported concerning the undrained cyclic behavior of reinforced gravel soil, because it takes a long time and is difficult to prepare the soil samples. Compared to many other soil types, gravel soil plays an essential role in the overall deformation behavior of railway subgrade. During the construction process, gravel material layer is compacted at the densest and stiffest possible state, which can be achieved by using the optimum moisture content defined by the Proctor compaction test. After years of railway operation, the unbound gravel soil layer is exposed in specific stress conditions and traffic loads. It is customary to use a constant elastic modulus as the stiffness index of soil in traditional engineering design, while ignoring the change of stiffness of soil during cyclic loading. Actually, even under the static loading conditions, the stiffness of gravel soil can be characterized by nonlinear softening as the strain increases gradually, and the dynamic behavior is more obvious under cyclic loading [17]. However, there is no information in the literature on the effect of dynamic elastic modulus of reinforced subgrade. Furthermore, stress and deformation state of reinforced soil and interaction mechanism between reinforced and soil under cyclic loading need to be studied.

The main purpose of this study is to evaluate the effects of influence factors on dynamic elastic modulus of reinforced subgrade. Experimental investigations of reinforced soil under cyclic loading based on orthogonal array design are conducted. A series of cyclic triaxial tests were carried out by varying confining pressure, vibration frequency, reinforced layers, and dynamic stress amplitudes. Effects of these parameters on the dynamic elastic modulus of reinforced subgrade are studied. Besides, the influence factors of dynamic elastic modulus and the changing rule with the factor were also studied according to the extreme value analysis. Finally, the results of the tests were analyzed and could provide theoretical foundation and further application for the reinforced soil.

\section{Cyclic Triaxial Tests}

2.1. Apparatus. These cyclic triaxial tests were carried out at the laboratory of Institute of Earthquake Engineering of Dalian University of Technology. This apparatus was equipped with a pressure chamber having a diameter of $20 \mathrm{~cm}$, height of $50 \mathrm{~cm}$, together with vibration equipment and measurement equipment was designed and fabricated. Maximum axial pressure is $150 \mathrm{kN}$, and maximum axial tension is $100 \mathrm{kN}$. Maximum axial displacement is $\pm 50 \mathrm{~mm}$. The biggest confining pressure is $3 \mathrm{MPa}$. Some higher frequency may be used because of the special test purpose, and the excitation system is usually set in the axial of instrument to provide different types of vibration loading. Three wave types can be adopted in test, which are impact type, periodic type, and arbitrary type, as shown in Figure 1.

Figure 2 shows the sketch of wave shape of cyclic loading. The parameters are as follows: $\sigma_{\max }$ is the maximum stress of cyclic loading; $\sigma_{\min }$ is the minimum stress of cyclic loading; $\Delta \sigma$ is amplitude load, $\Delta \sigma=\sigma_{\max }-\sigma_{\min } ; T$ is cyclic of vibration; and $f$ is frequency and $f=1 / T$. 


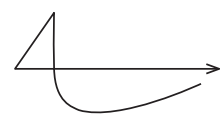

(a)

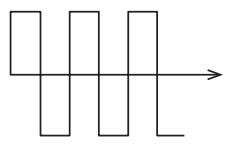

Rectangular wave

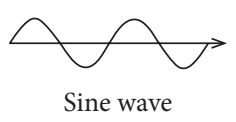

(b)

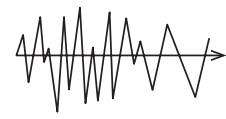

(c)
Figure 1: Schematic diagram of dynamic load waveform. (a) Impact type. (b) Periodic type. (c) Arbitrary type.

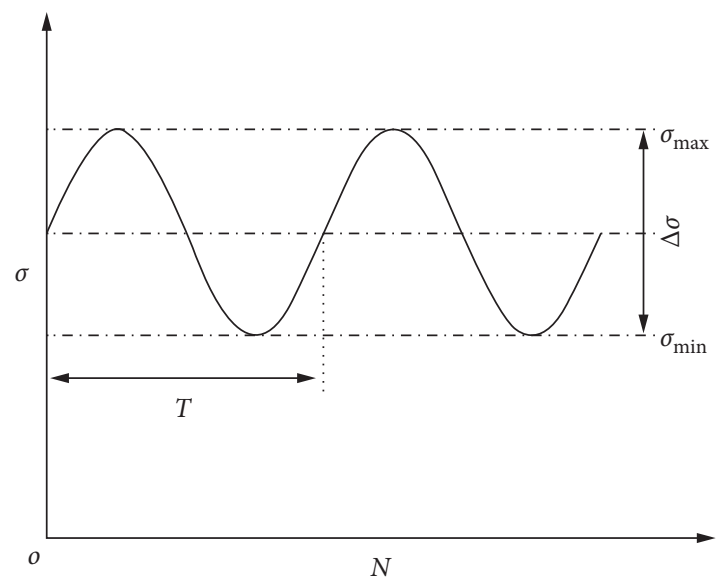

FIgURE 2: Sketch of wave shape of cyclic loading.

The vibration frequency varied from $0.1 \mathrm{~Hz}$ to $10 \mathrm{~Hz}$. The instrument was equipped with displacement sensor and force sensor. Experimental data can be collected and analyzed automatically. High-precision hydraulic servo medium triaxial testing system is designed by anti-Semitic research institute of Dalian University of Technology by using computer and hydraulic servo technique. It was used in this experiment. A detailed sketch and a photo of the apparatus are shown in Figure 3.

\subsection{Materials}

2.2.1. Gravel Soil. The soil used in this study was gravel soil and was obtained from the subgrade bed of the railway track in the region of Dalian, north of China. The samples were collected in a disturbed state, by manual excavation, in sufficient quantity to complete all the tests. The coefficient of uniformity, $\mathrm{Cu}$, is 17.5 and the coefficient of gradation, $\mathrm{Cc}$, is 1.03. Figure 4 plots the resultant particle size distribution curve. This gravel soil sample has a good gradation and is the most commonly used as filling in the actual projects, and the essential physical parameters of soil are shown in Table 1.
2.2.2. Geogrid. In this study, the TGSG40-40 Bidirectional plastic geogrid was used as reinforced material. Geogrid is made of high-density polyethylene (HDPE) by thermoplastic or molded, and it is manufactured by Shandong Feicheng Lianyi Engineering Plastics limited company, China. The outlook of the Bidirectional (Biaxial) plastic geogrid is network structure like a square, and made of high-molecular polymer as its raw material through extrusion, formed and punched before longitudinally and laterally stretched. This geogrid has high tensile strength in both longitudinal and horizontal directions and provides an ideal interlocking system. It can be widely used to all kinds of roads, railways, and airports to enhance the bearing capacity of subgrade bed, to enhance slope stability, and to extend the service life of subgrade. Figure 5 shows the TGSG40-40 Bidirectional plastic geogrid that has been used as reinforcement. In order to reduce friction between geogrid and pressure chamber during the experiment, the geogrid is cut as shown in Figure 5. Physical property of geogrid is shown in Table 2.

2.3. Sample Preparation. The samples were prepared in cylindrical molds with a height of $50 \mathrm{~cm}$ and a diameter of $20 \mathrm{~cm}$. The test started with vacuum extraction between mold and rubber for sample package, and then soil specimens were put by vibrating in the mold in five sequential layers. After a final setting, every filling height is $10 \mathrm{~cm}$ and was checked with a steel gauge. Taking into account the apparatus, three reinforcement ways can be used in the test. The first way, the soil sample is not reinforced. The second way, a layer of geogrid was placed in the middle of the sample. The third way, a layer of geogrid was placed in the middle and lower part of the mold, and another layer of geogrid was placed in the middle and top of the mold. The specimens were prepared at a density equal to approximately $96 \%$ of the maximum density at the optimum moisture content in each step. The geogrid is laid horizontally. Geogrid placement diagram is shown in Figure 6.

2.4. Test Scheme. There are many technical parameters affecting the test result. The orthogonal array design allows to limit the amount of research needed to achieve the desired test results, reducing the time required course for their performance and at the same time reducing costs. It is an effective way to design an experiment to find out the most influential factor. The orthogonal array with two advantages of uniformly dispersed, neat, and comparable making each test is highly representative, so the fewer times of experiments can fully reflect the impact of the different levels of each factor on the index.

The effect degree of confining pressure, reinforced way, dynamic stress amplitude, and frequency were analyzed, respectively, through orthogonal design of experiments in four factors and three levels. For better simulating dynamic characteristic of geogrid reinforced soil, different dynamic stress amplitudes were selected to simulate dynamic responses, which are caused by train with different speed or axle weight. Calculation table of dynamic stress amplitude is shown in Table 3. 


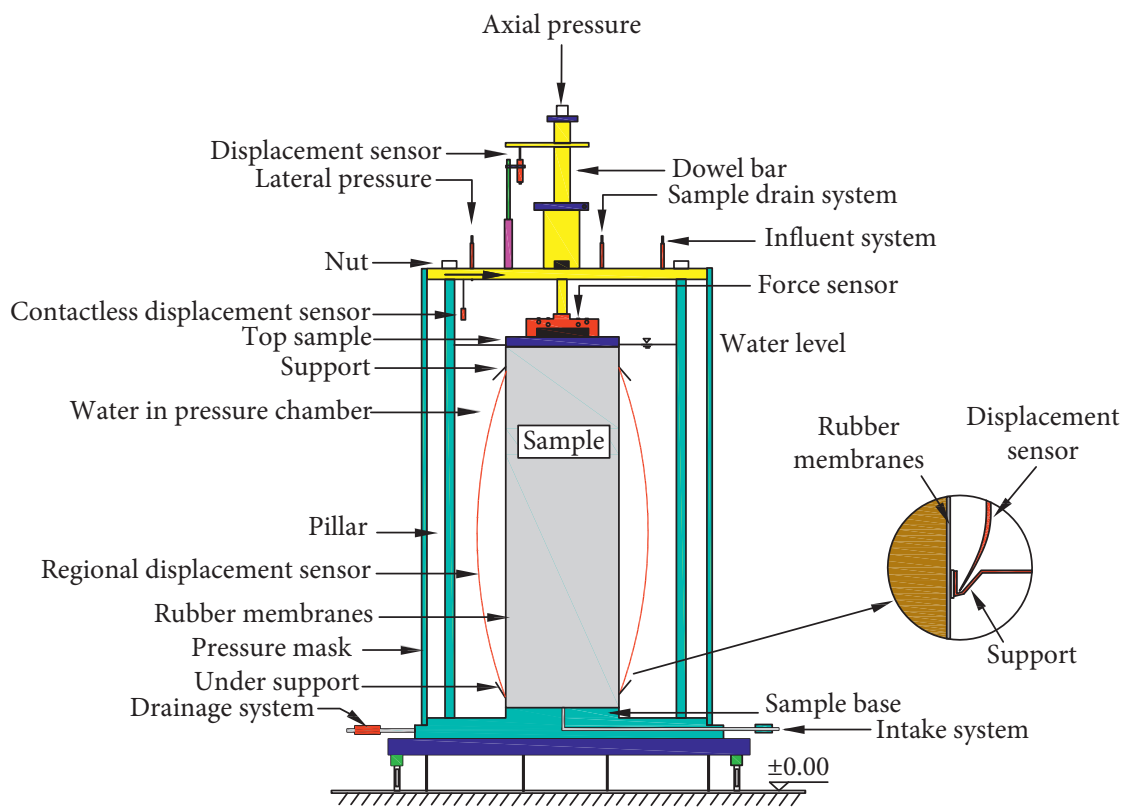

(a)

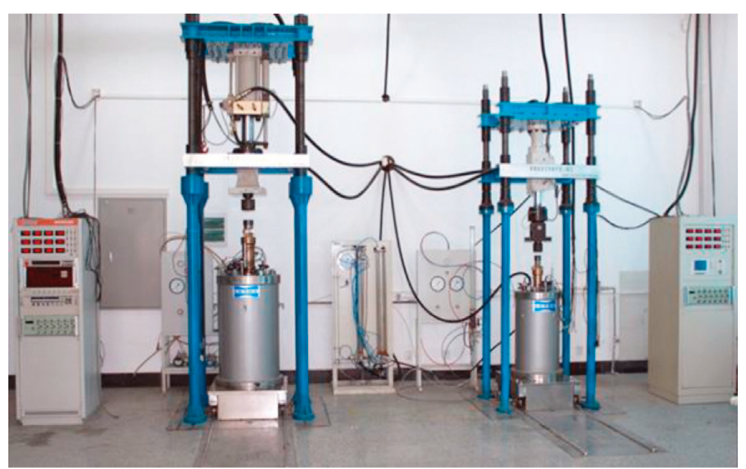

(b)

Figure 3: (a) A detailed sketch and (b) a photo of cyclic triaxial apparatus.

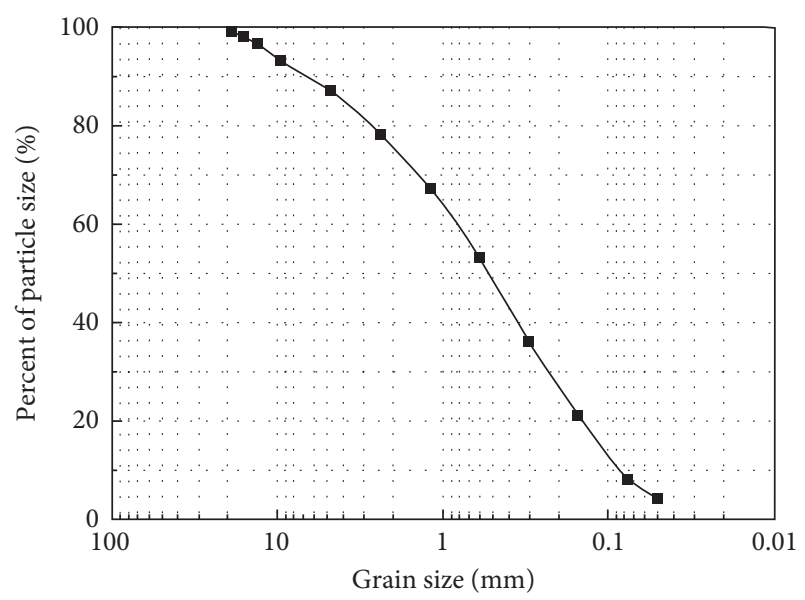

Figure 4: Particle size distribution of soil sample.

Three different confining pressures $60 \mathrm{kPa}, 90 \mathrm{kPa}$, and $150 \mathrm{kPa}$ are considered for simulating specific conditions in the case of railway subgrade.
TABLE 1: Essential physical parameters of soil.

\begin{tabular}{lc}
\hline Description/property & Value \\
\hline Natural water content & $5 \%$ \\
Liquid limit & $26 \%$ \\
Plastic limit & $21 \%$ \\
Plasticity index & 5 \\
Cohesion & $15.55\left(\mathrm{kN} / \mathrm{m}^{2}\right)$ \\
Angle of friction & $19.5^{\circ}$ \\
Optimum moisture content (OMC) & $18 \%$ \\
Maximum dry density (MDD) & $2.1\left(\mathrm{kN} / \mathrm{m}^{3}\right)$ \\
Maximum particle size & $25 \mathrm{~mm}$ \\
\hline
\end{tabular}

Considering the transient in the vibration of the subgrade during the long-term effect of the train loads, the filling was not drained by instantaneous drainage, so that the experiment was performed without drainage. The cyclic loading of different trains is simulated with MTS servo exciter. Unsaturated specimens were tested under undrained triaxial compression using monotonic and cyclic loading with frequencies in the range of $0.5 \sim 2 \mathrm{~Hz}$. Sine wave was used in this study to simulate traffic loads with short 


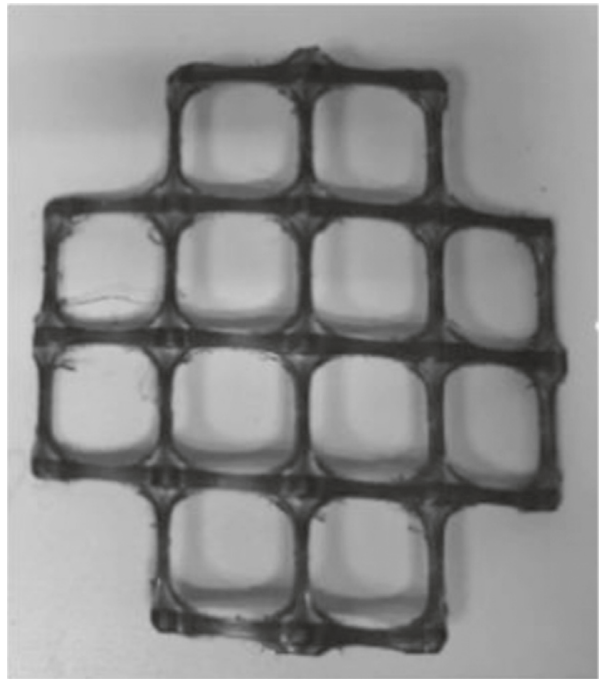

FIgURE 5: Bidirectional plastic geogrid.

TABle 2: Physical property of geogrid.

\begin{tabular}{lc}
\hline Geometrical/physical characteristics & Value \\
\hline Raw material & Polypropylene \\
Aperture size, (transverse length), $A_{\mathrm{L}}$ & $35 \mathrm{~mm}$ \\
Aperture size, (longitudinal length), $A_{\mathrm{L}}$ & $35 \mathrm{~mm}$ \\
Tensile strength (MD/CD) & $\geq 40 \mathrm{kN} / \mathrm{m}$ \\
Tensile strength at $2 \%$ elongation & $\geq 14$ \\
Tensile strength at $5 \%$ elongation & $\geq 28$ \\
Mass area ratio & $500 \pm 50 \mathrm{~g} / \mathrm{m}$ \\
\hline
\end{tabular}

vibration cycle and more vibration. The consolidation stress ratio, $\mathrm{Kc}$, is 1 . There are three situations of reinforcement in the test, that is, no geogrid, one layer of geogrid, and two layers of geogrid. The orthogonal array of the tests is provided in Table 4.

\section{Results and Discussion}

3.1. Dynamic Properties of Railway Subgrade under Cyclic Loading. With the increase of vibration frequency, the fluctuation of dynamic stress increment increases. After about ten thousand times of vibration, the dynamic stress increment gradually tends to oscillate in a stable interval. Because the test data are intensive and unstable in the early cycles, some of the test data in midterm test were selected to be enlarged, as shown in Figure 7. It shows the dynamic stress's time range curve under cycle loading of 9 tests $(N$ represents the number of load cycles). The dynamic stress increment is basically stable in the whole vibration process except a small fluctuation at some areas.

Figure 8 shows the relation curve of dynamic elastic modulus and dynamic strain. It may be seen from Figure 8 that with the increase of dynamic strain amplitude, the dynamic elastic modulus $\left(E_{\mathrm{d}}\right)$ decreases gradually, that is, strain softening occurs. When $\varepsilon_{\mathrm{d}}<0.25 \%$ at the initial stage of the cycle, the curve is steep and the attenuation rate of $E_{\mathrm{d}}$ is faster; when the dynamic strain is greater than $0.25 \%$, the curve tends to be gentle, and the attenuation rate of $E_{\mathrm{d}}$ tends to be 0 . Overall, the curve (the image of a power function) obtained by applying interpolation with respect to the dynamic elastic modulus is convergent.

3.2. Maximum Dynamic Elastic Modulus. Maximum dynamic elastic modulus $\left(E_{\mathrm{d} \max }\right)$ is usually used as the design parameter in project. To quantify the dynamic behavior under cycle loading of reinforced soil, maximum dynamic elastic modulus can be defined based on curve. It can be observed that the measured data are distributed by Hardin hyperbola by analysis; that is, the dynamic constitutive relation of reinforced soil conforms to hyperbolic model, which is defined as follows:

$$
E_{\mathrm{d}}^{-1}=a+b \varepsilon_{\mathrm{d}}
$$

where $E_{\mathrm{d}}$ is the dynamic elastic modulus, $a$ and $b$ are fitting parameters, and $\varepsilon_{\mathrm{d}}$ is the dynamic strain. From Formula (1), $\varepsilon_{\mathrm{d}}=0,1 / a$ represents the maximum dynamic elastic modulus of reinforced soil sample $E_{\mathrm{d} \max }$. The results are shown in Table 5.

According to the maximum elastic modulus, the order of influence factor is determined by means of range analysis, and the results are shown in Table 6 .

Using range analysis through orthogonal design of experiments, the order of influence factor to dynamic elastic modulus in the test is determined within three factor levels. They are dynamic stress amplitude, frequency, reinforced layer, and confining pressure. That is, the influence of confining pressure to reinforced soil is the greatest.

3.3. Analysis of Significant Influencing Factors. The order of influence factor of reinforced soil can be determined though range analysis, but there are no comparison between the result caused by changing of factor and level and the result caused by experimental error. There is no standard to measure its significance. To solve this problem, variance 


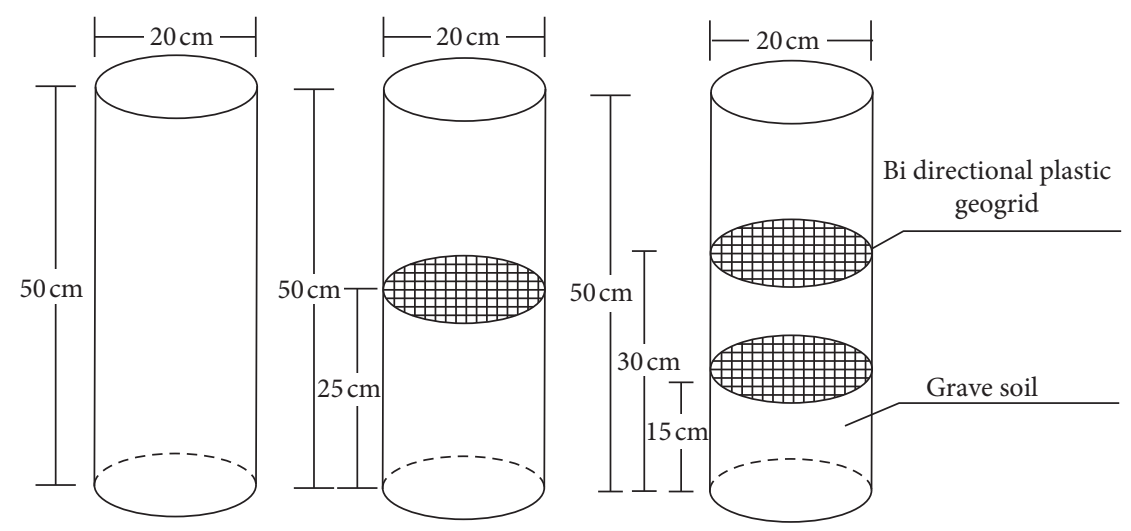

Figure 6: Geogrid placement diagram.

TABLE 3: Calculation table of dynamic stress amplitude.

\begin{tabular}{lcccc}
\hline $\begin{array}{l}\text { Axle weight } \\
(\mathrm{T})\end{array}$ & $\begin{array}{c}\text { Axle weight } \\
(\mathrm{kN})\end{array}$ & $\begin{array}{c}\text { Speed } \\
(\mathrm{km} / \mathrm{h})\end{array}$ & $\sigma_{\mathrm{d}}^{\prime}(\mathrm{kPa})$ & $\sigma_{\mathrm{d}}(\mathrm{kPa})$ \\
\hline 20 & 196 & 120 & 69.3 & 70 \\
25 & 245 & 100 & 82.8 & 80 \\
30 & 294 & 80 & 94.8 & 95 \\
\hline
\end{tabular}

$\sigma_{\mathrm{d}}^{\prime}$ is a calculated value of dynamic stress amplitude by the formula $\sigma_{\mathrm{d}}^{\prime}=$ $0.26 \times P \times(1+0.003 V) . P$ is the axle weight and $V$ is the speed. To simplify the test, we denote by $\sigma_{\mathrm{d}}$ the value of dynamic stress amplitude taken in the test.

TABLe 4: The orthogonal array.

\begin{tabular}{lcccc}
\hline Group & $\sigma_{c}(\mathrm{kPa})$ & $\sigma_{d}(\mathrm{kPa})$ & $f(\mathrm{~Hz})$ & Number of reinforced layers \\
\hline 1 & 56 & 70 & 1 & 0 \\
2 & 56 & 80 & 2 & 1 \\
3 & 56 & 95 & 0.5 & 2 \\
4 & 90 & 70 & 2 & 2 \\
5 & 90 & 80 & 0.5 & 0 \\
6 & 90 & 95 & 1 & 1 \\
7 & 150 & 70 & 0.5 & 1 \\
8 & 150 & 80 & 1 & 2 \\
9 & 150 & 95 & 2 & 0
\end{tabular}

$\sigma_{\mathrm{c}}$ is confining pressure, $f$ is frequency. In addition, it was difficult to prepare exact soil samples in cyclic triaxial tests, and there is an error during the operation of the instrument and acquisition process of the data. Therefore, it is necessary to make variance analysis on the test results.

analysis can be taken in this study. The results of variance analysis of orthogonal experiment are shown in Table 7. Variance analysis of orthogonal experiments is shown that the dynamic elastic modulus of reinforced soil is significantly affected by dynamic stress amplitude. The effect of reinforced layer on dynamic elastic modulus of reinforced soil is significant. It has been identified that frequency and confining pressure have an insignificant influence.

3.3.1. Effects of Dynamic Stress Amplitude. The dynamic response of reinforced subgrade, which is caused by train with different axle load and speed, can be simulated by dynamic stress amplitude. When dynamic stress is small, the strength and stiffness of soil samples are basically unchanged and the dynamic stress amplitude and dynamic strain are basically unchanged. Dynamic stress increases with increasing the dynamic stress amplitude. At this moment, the structure of soil samples changes and the soil particles tend to be close to each other and the dynamic strain and pore pressure gradually increase. With the increase of vibration frequency, soil samples are deformed, the performance of strength and stiffness decreased, the bearing capacity of soil samples are reduced, and the elastic modulus of soil samples decreased gradually. It is noteworthy that the dynamic stress amplitude has the greatest influence on the dynamic elastic modulus of reinforced soil. The demonstration results are consistent with the fact that heavy-axle load trains cause more dynamic stress than the light-axle load trains in engineering.

3.3.2. Effects of Frequency. The dynamic effect caused by different speed train passing the reinforced subgrade can be stimulated by different vibration frequency. Accumulated strain of soil is related to vibration frequency under the same vibrations. With the increase of frequency, the dynamic strain of soil increased. Relative to conventional railway, it can be easily obtained from the dynamic strain in high-speed railway and the developing rate of strain is faster. Within a certain dynamic strain range, dynamic elastic modulus is increasing with the increase of frequency.

3.3.3. Effects of Reinforced Layer. The experimental results showed the dynamic elastic modulus gradually decrease with the increase of reinforced layer. The dynamic elastic modulus of plain soil is greater than that with only one layer of reinforcement, which is greater than that with two layers of reinforcement. Since this study is based on experiments with reinforced layers less than two, more study is needed to investigate the effect of dynamic elastic modulus.

3.3.4. Effects of Confining Pressure. As mentioned previously, different embedded depth of TGSG geogrid can be demonstrated by confining pressure to some extent. The effect of confining pressure plays a minor role of the dynamic elastic modulus. The test results further show that the 


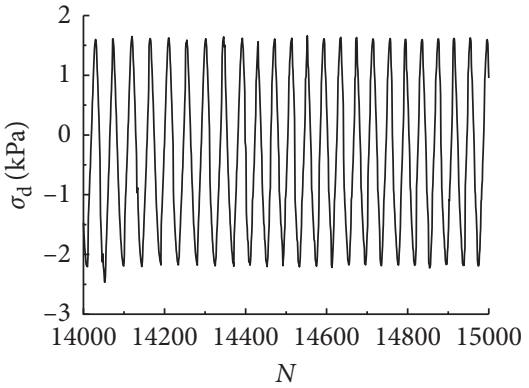

(a)

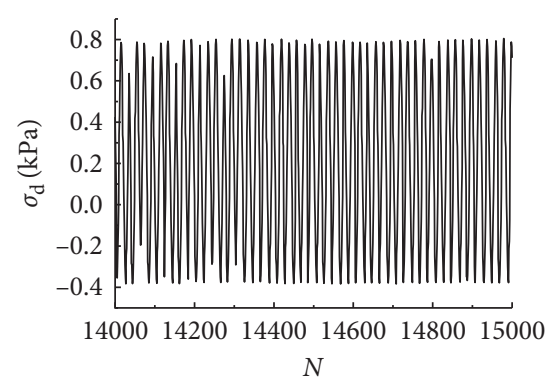

(d)

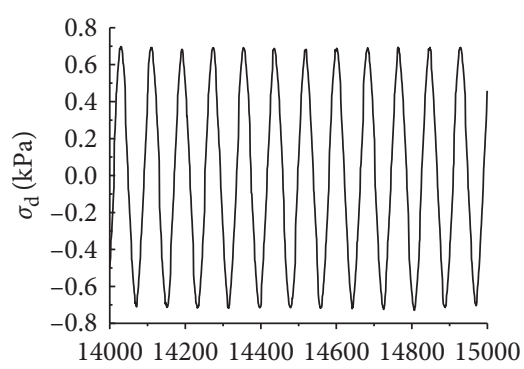

N

(g)

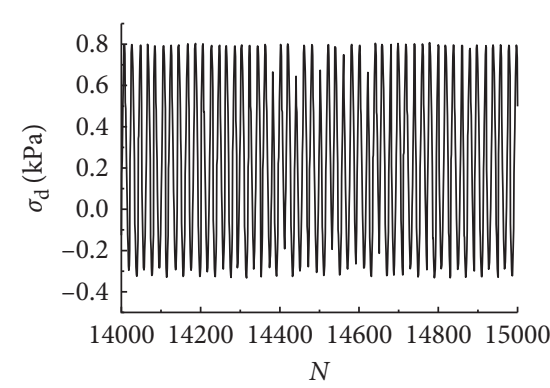

(b)

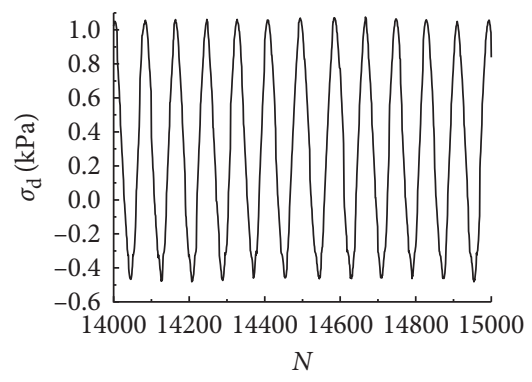

(e)

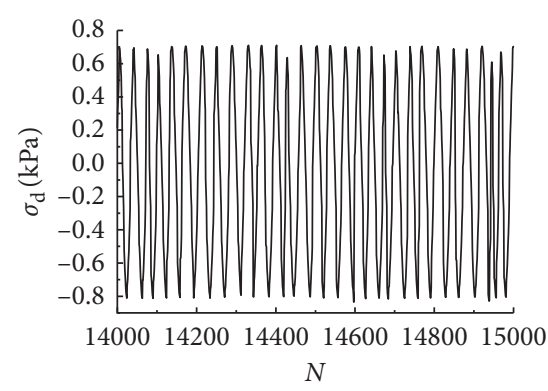

(h)

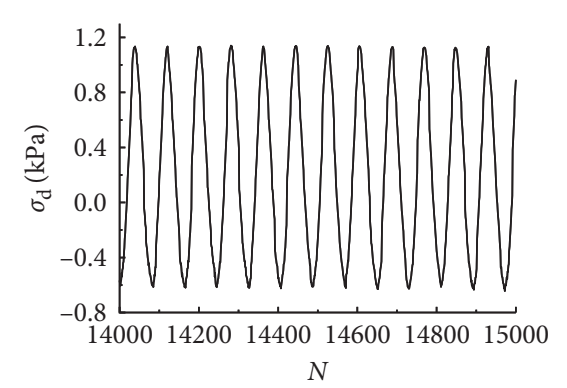

(c)

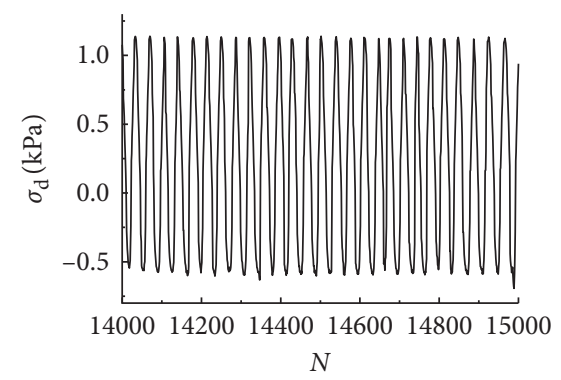

(f)

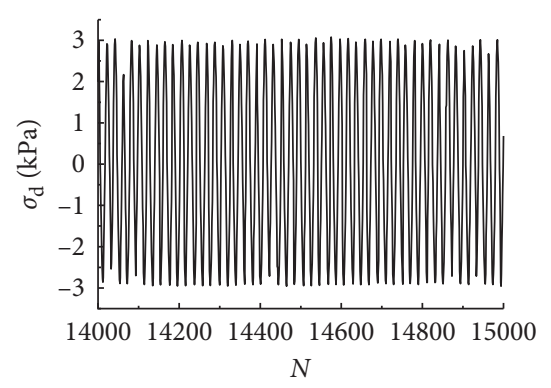

(i)

Figure 7: Dynamic stress time-history curves.

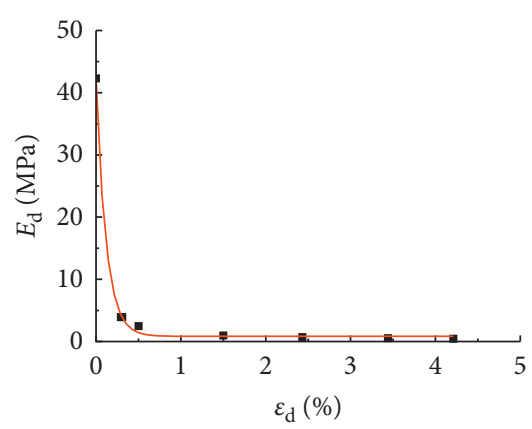

(a)

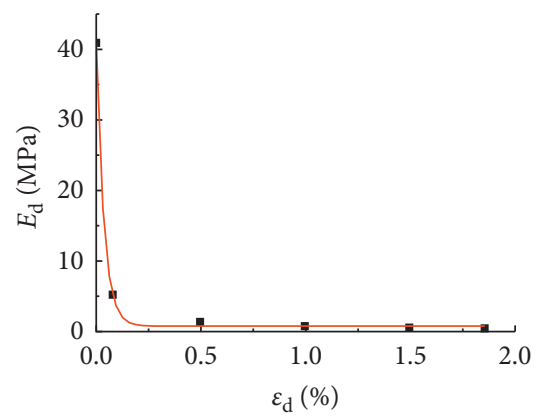

(b)

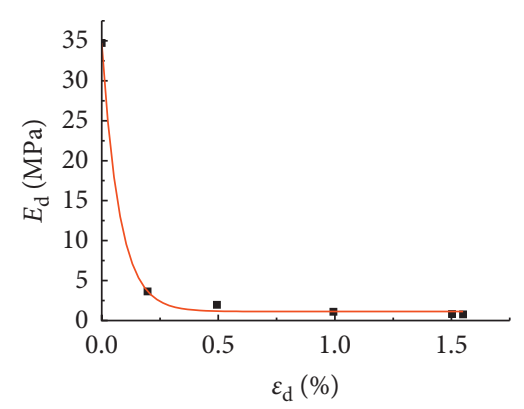

(c)

FIgure 8: Continued. 


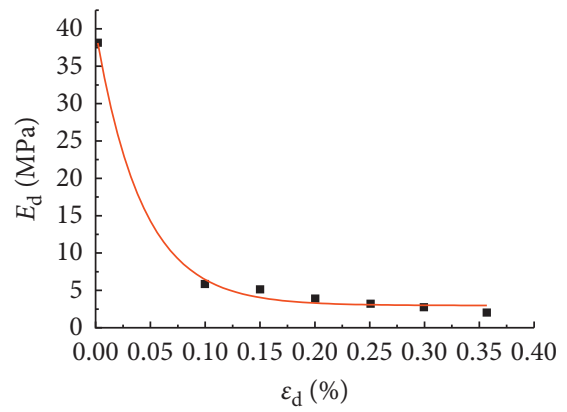

(d)

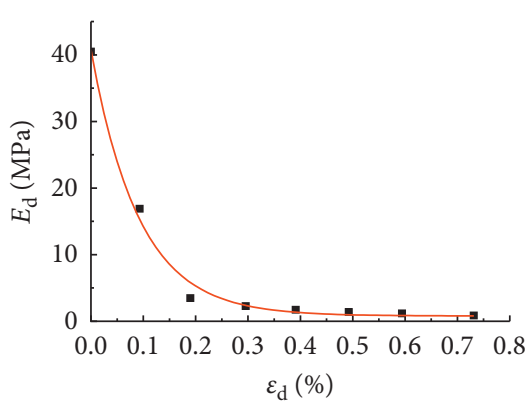

$(\mathrm{g})$

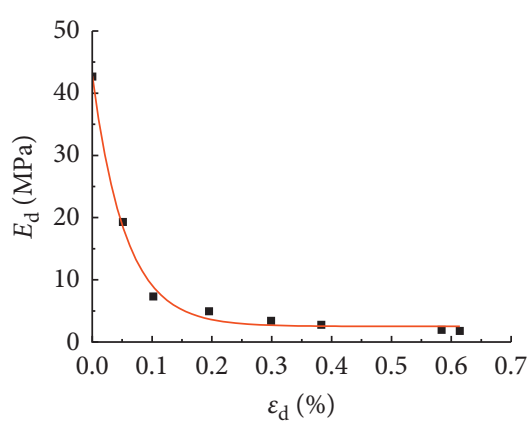

(e)

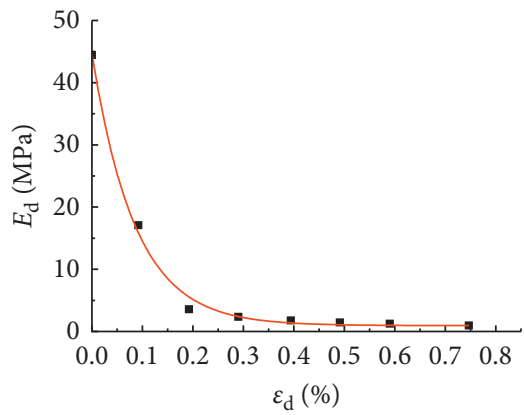

(h)

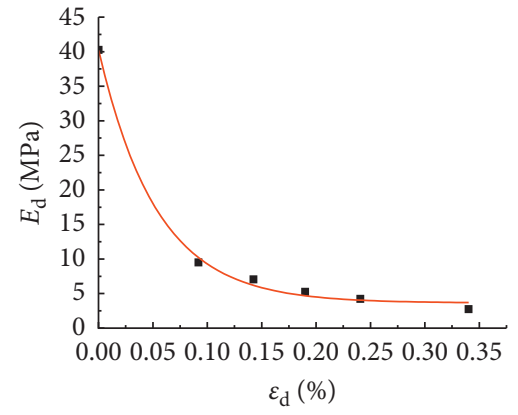

(f)

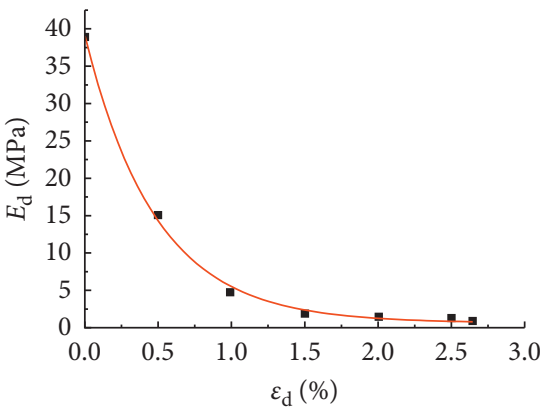

(i)

Figure 8: Curves for $E_{\mathrm{d}}-\varepsilon_{\mathrm{d}}$.

TABLe 5: Maximus dynamic elastic modulus and test parameters under different test conditions.

\begin{tabular}{lccc}
\hline Group & $a\left(\mathrm{MPa}^{-1}\right)$ & $b\left(\mathrm{MPa}^{-1}\right)$ & $E_{\mathrm{dmax}}(\mathrm{MPa})$ \\
\hline 1 & 0.02333 & 0.76459 & 42.86 \\
2 & 0.02411 & 2.05189 & 41.48 \\
3 & 0.02873 & 0.08323 & 34.81 \\
4 & 0.02597 & 1.25684 & 38.51 \\
5 & 0.02318 & 1.30546 & 43.14 \\
6 & 0.02465 & 0.86946 & 40.57 \\
7 & 0.02461 & 1.34147 & 40.63 \\
8 & 0.02228 & 1.32149 & 44.88 \\
9 & 0.02538 & 0.34307 & 39.40 \\
\hline
\end{tabular}

adopted confining pressure with a small difference (between $60 \mathrm{kPa}$ and $90 \mathrm{kPa}$ or between $90 \mathrm{kPa}$ and $150 \mathrm{kPa}$ ) can affect the test precision, because the test apparatus can apply $3 \mathrm{MPa}$ confining pressure. It is observed that plastic deformation of soil can be resisted by increasing confining pressure; therefore, it improves the antideformation ability of soil.

\section{Conclusion}

Undrained cyclic triaxial tests have been carried out using orthogonal design of experiment. The influence factors of the dynamic elastic modulus of reinforced subgrade were studied in this paper. Impacts of confining pressure, dynamic stress amplitude, frequency, and reinforced layer on dynamic elastic modulus are discussed. The order of dynamic elastic modulus of reinforced soil is influenced by
TABLE 6: Results of orthogonal design of experiment.

\begin{tabular}{lccccc}
\hline Group & $\sigma_{\mathrm{c}}(\mathrm{kPa})$ & $\sigma_{\mathrm{d}}(\mathrm{kPa})$ & $f(\mathrm{~Hz})$ & $\begin{array}{c}\text { Reinforced } \\
\text { layer }\end{array}$ & $\begin{array}{c}E_{\mathrm{dmax}} \\
(\mathrm{MPa})\end{array}$ \\
\hline 1 & 56 & 70 & 1 & No & 42.86 \\
2 & 56 & 80 & 2 & One & 41.48 \\
3 & 56 & 95 & 0.5 & Two & 34.81 \\
4 & 90 & 70 & 2 & Two & 38.51 \\
5 & 90 & 80 & 0.5 & No & 43.14 \\
6 & 90 & 95 & 1 & One & 40.57 \\
7 & 150 & 70 & 0.5 & One & 40.63 \\
8 & 150 & 80 & 1 & Two & 44.88 \\
9 & 150 & 95 & 2 & No & 39.40 \\
$y_{j 1}$ & 119.15 & 122.00 & 128.31 & 125.40 & - \\
$y_{j 2}$ & 122.22 & 129.50 & 119.39 & 122.68 & - \\
$y_{j 3}$ & 124.91 & 114.78 & 118.58 & 118.20 & - \\
\hline$y_{j 1}$ & 39.72 & 40.67 & 42.77 & 41.80 & - \\
\hline$y_{j 2}$ & 40.74 & 43.17 & 39.80 & 40.89 & - \\
$y_{j 3}$ & 41.64 & 38.26 & 39.53 & 39.40 & - \\
Range & 1.92 & 4.91 & 3.24 & 2.40 & - \\
Order & 4 & 1 & 2 & 3 & - \\
\hline
\end{tabular}

$y_{j 1}$ is the sum of $E_{\mathrm{dmax}}$ 's obtained from each group when $\sigma_{\mathrm{c}}=56 \mathrm{kPa}, y_{j 2}$ is the sum of $E_{\mathrm{dmax}}$ 's obtained from each group when $\sigma_{\mathrm{c}}=90 \mathrm{kPa}, y_{j 3}$ is the sum of $E_{\mathrm{dmax}}$ 's obtained from each group when $\sigma_{\mathrm{c}}=150 \mathrm{kPa}$, and $\overline{y_{j x}}=y_{j x} / 3$, for $x=1,2,3$.

dynamic stress amplitude, frequency, reinforced layer, and confining pressure within changing in factor level.

The dynamic stress amplitude has a marked influence on the dynamic elastic modulus of reinforced soil. With the low dynamic stress, dynamic stress amplitude and dynamic strain are basically unchanged. With the increase of dynamic 
TABLE 7: Results of variance analysis of orthogonal design of experiment.

\begin{tabular}{lcccc}
\hline Sources of variation & $S_{j}$ & $f_{j}$ & $\overline{S_{j}}$ & $F_{j}$ \\
\hline Confining pressure & 0.615 & 2 & 0.308 & 1.000 \\
Dynamic stress amplitude & 4.013 & 2 & 2.007 & $36.58^{* *}$ \\
Frequency & 2.159 & 2 & 1.080 & 2.906 \\
Reinforced layer & 0.979 & 2 & 0.490 & $12.679^{*}$ \\
Error & 0.002 & 3 & 0.001 & \\
Sum & 7.768 & 11 & & \\
\hline
\end{tabular}

$\alpha=0.99,0.95$, and 0.90 quantiles of $F$ distribution with degrees of freedom 2 and 3 are $30.8,9.55$, and 5.45, i.e., $F_{0.99}(2,3)=30.8, F_{0.95}(2,3)=9.55$, and $F_{0.90}(2,3)=5.46 . S_{j}$ is the sum of squares in $j$ rows; $f_{j}$ is the degree of freedom; $\overline{S_{j}}$ is sum of average column variation; $F_{j}$ is test statistics; * presents significant influence when $\alpha=0.05$; * presents significant influence particularly when $\alpha=0.01$; for a given level of significance a, when $F_{j}>F_{1-\alpha}(2,3)$, under test level $\alpha$, the factor is inferred to be outstanding, otherwise it is regarded as nonsignificant. $\alpha$ is less, and it demonstrated that the effect of this factor to test results is significant.

stress, dynamic stress amplitude increases correspondingly and the soil particles tend to be close to each other. The bearing capacity of reinforced soil decreases and dynamic elastic modulus decreases slightly with the increase of dynamic strain.

Frequency has an influence on the dynamic elastic modulus. It is shown that the cumulative strain of reinforced soil is related to the vibration frequency. The higher the frequency is, the greater the strain caused by subgrade is. $E_{\mathrm{d}}$ increases as the vibration frequency goes up within a certain dynamic strain range. Reinforced layer has influence on the dynamic elastic modulus. With the increase of reinforced layer, the dynamic elastic modulus is decreasing gradually. The test results also exemplify the reinforced subgrade restrict lateral displacement of subgrade and reduce settlement of subgrade under long-term cyclic loading.

It should be noted that the study of dynamic behavior of reinforced soil is much needed in order to further address reinforced soil application.

\section{Conflicts of Interest}

The authors declare that they have no conflicts of interest.

\section{Acknowledgments}

This academic research work was supported by the Doctoral Scientific Research Foundation of Liaoning Province of China (201601255), Scientific Research Foundation of Ministry of Education of Liaoning Province of China (JDL2016017), National Natural Science Foundation of China (51408093), and Natural Science Foundation of Liaoning Province of China (21070540134). The authors thank Chenguang Zhou and Jirong Tian for their help in construction of the physical models and contributions during the cyclic triaxial tests. The authors appreciate the efforts of Qing Yang for reading the manuscript and making valuable suggestions. The authors also wish to thank the anonymous reviewers for their critical comments.

\section{References}

[1] B. Indraratna, D. Ionescu, and D. Christie, "Shear behavior of railway ballast based on large scale triaxial testing," Journal of Geotechnical Geoenvironmental Engineering, vol. 124, no. 5, pp. 439-449, 1998.

[2] H. S. Li, G. L. Yang, and Y. S. Zou, "Analysis of dynamic character of reinforced earth retaining wall," China Journal of Highway and Transport, vol. 17, no. 2, pp. 28-31, 2004.

[3] T. Tanchaisawat, D. T. Bergado, and P. Voottipruex, "Numerical simulation and sensitivity analyses of full-scale test embankment with reinforced lightweight geomaterials on soft Bangkok clay," Geotextiles and Geomembranes, vol. 26, no. 6, pp. 498-511, 2008.

[4] Y. Q. Tang, Y. L. Wang, Y. Huang, and Z. Y. Zhou, "Dynamic strength and dynamic stress-strain relation of silt soil under traffic loading," Journal of Tongji University (Natural Science), vol. 32, no. 6, pp. 701-704, 2004.

[5] J. Zhou and X. N. Gong, "Study on strain soften in saturated soft clay under cyclic loading," China Civil Engineering Journal, vol. 33, no. 5, pp. 75-82, 2000.

[6] M. E. Magdi and J. B. Richard, "Influence of reinforcement parameters in the seismic response of reduce-scale reinforced soil retaining walls," Geotextiles and Geomembranes, vol. 25, no. 1, pp. 33-49, 2007.

[7] G. L. Yang, H. S. Li, and Y. H. Wang, "Model test on reinforced earth retaining wall under repeated load," China Civil Engineering Journal, vol. 36, no. 6, pp. 105-110, 2003.

[8] D. G. Zou, J. Bi, B. Xu, X. J. Kong, and Y. Zhao, "Research on the residual deformation behavior of sand-gravel composites reinforced with geogrid," Journal of Hydroelectric Engineering, vol. 28 , no. 5, pp. 158-162, 2009.

[9] M. S. Masoud and H. B. Farhad, "Dynamic behavior of reinforced clayey sand under cyclic loading," Geotextiles and Geomembranes, vol. 42, no. 5, pp. 564-572, 2014.

[10] J. Li and D. W. Ding, "Nonlinear elastic behavior of fiberreinforced soil under cyclic loading," Soil dynamics and earthquake engineering, vol. 22, no. 9-12, pp. 977-983, 2002.

[11] G. Iman, G. Abbas, K. J. Mohammad, and M. Mehdi, "Dynamic properties of polyurethane foam-sand mixtures using cyclic triaxial tests," Construction and Building Materials, vol. 118, pp. 104-115, 2017.

[12] L. Stanislav, K. Junichi, M. Yukika, and S. Takeshi, "Large-scale triaxial tests of dense gravel material at low confining pressures," Soils and Foundations, vol. 54, no. 1, pp. 45-55, 2014.

[13] Y. Li, G. L. Yang, and Y. L. Lin, "Dynamic characteristics of reinforced gabion walls subjected to cyclic loading," Journal of Highway and Transportation Research and Development, vol. 28, no. 2, pp. 1-6, 2011.

[14] H. Aliakbar, T. Ahmadreza, S. Hossein, and H. T. Saeed, "Effect of stress conditions on collapse deformation behavior of a rockfill material," KSCE Journal of Civil Engineering, vol. 19, no. 6, pp. 1637-1646, 2015.

[15] L. Verrucci, G. Lanzo, P. Tommasi, and T. Rotonda, "Cyclic and dynamic behavior of a soft pyroclastic rock," Geotechnique, vol. 65, no. 5, pp. 359-373, 2015.

[16] R. Jamshidi, I. Towhata, H. Ghiassian, and A. R. Tabarsa, "Experimental evaluation of dynamic deformation characteristics of sheet pile retaining walls with fiber reinforced backfill," Soil Dynamics and Earthquake Engineering, vol. 30, no. 6, pp. 438-446, 2010.

[17] F. Y. Liu, Y. Q. Cai, C. J. Xu, and J. Wang, "Degradation of dynamic elastic modulus of soft clay under cyclic loading," Journal of Zhejiang University (Engineering Science), vol. 42, no. 9, pp. 1479-1483, 2008. 


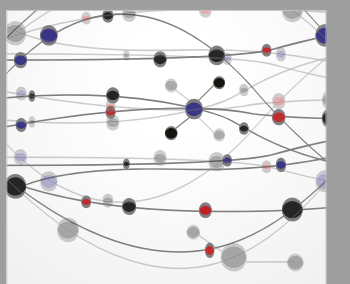

The Scientific World Journal
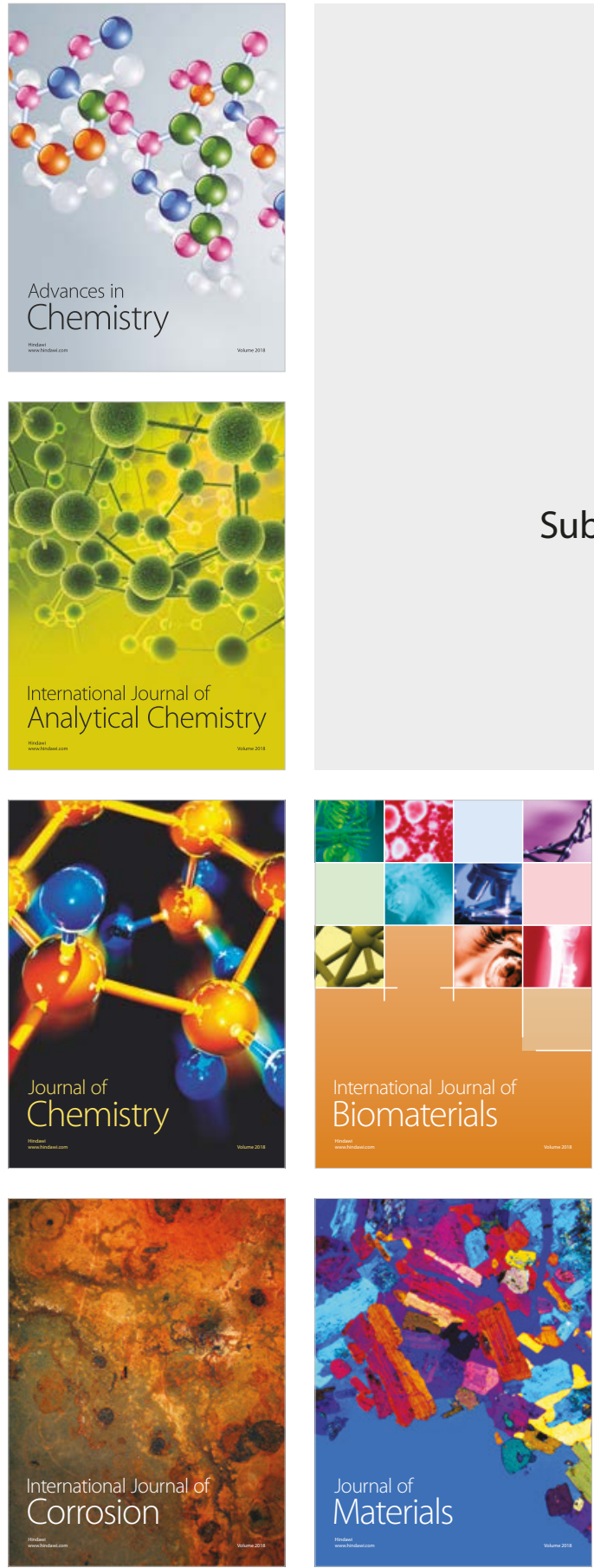

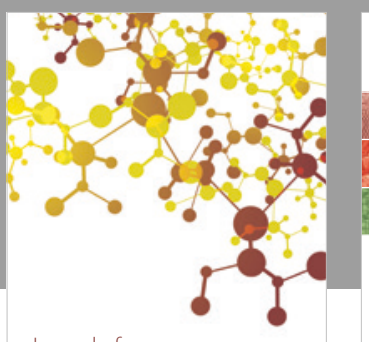

Journal of

Applied Chemistry
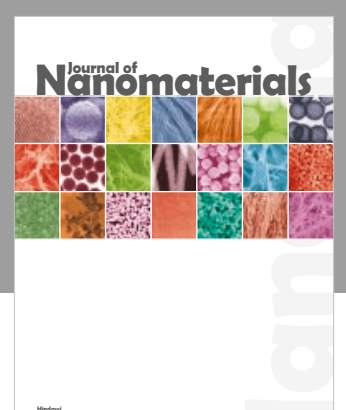

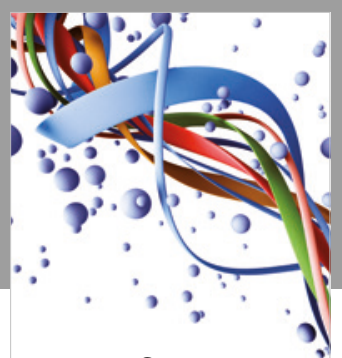

Scientifica

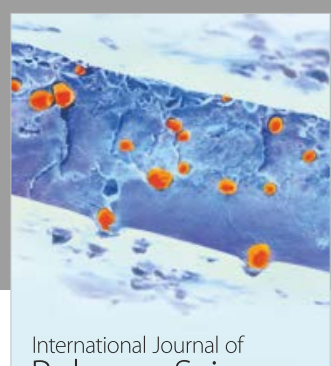

Polymer Science

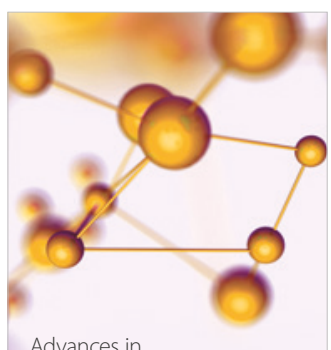

Physical Chemistry
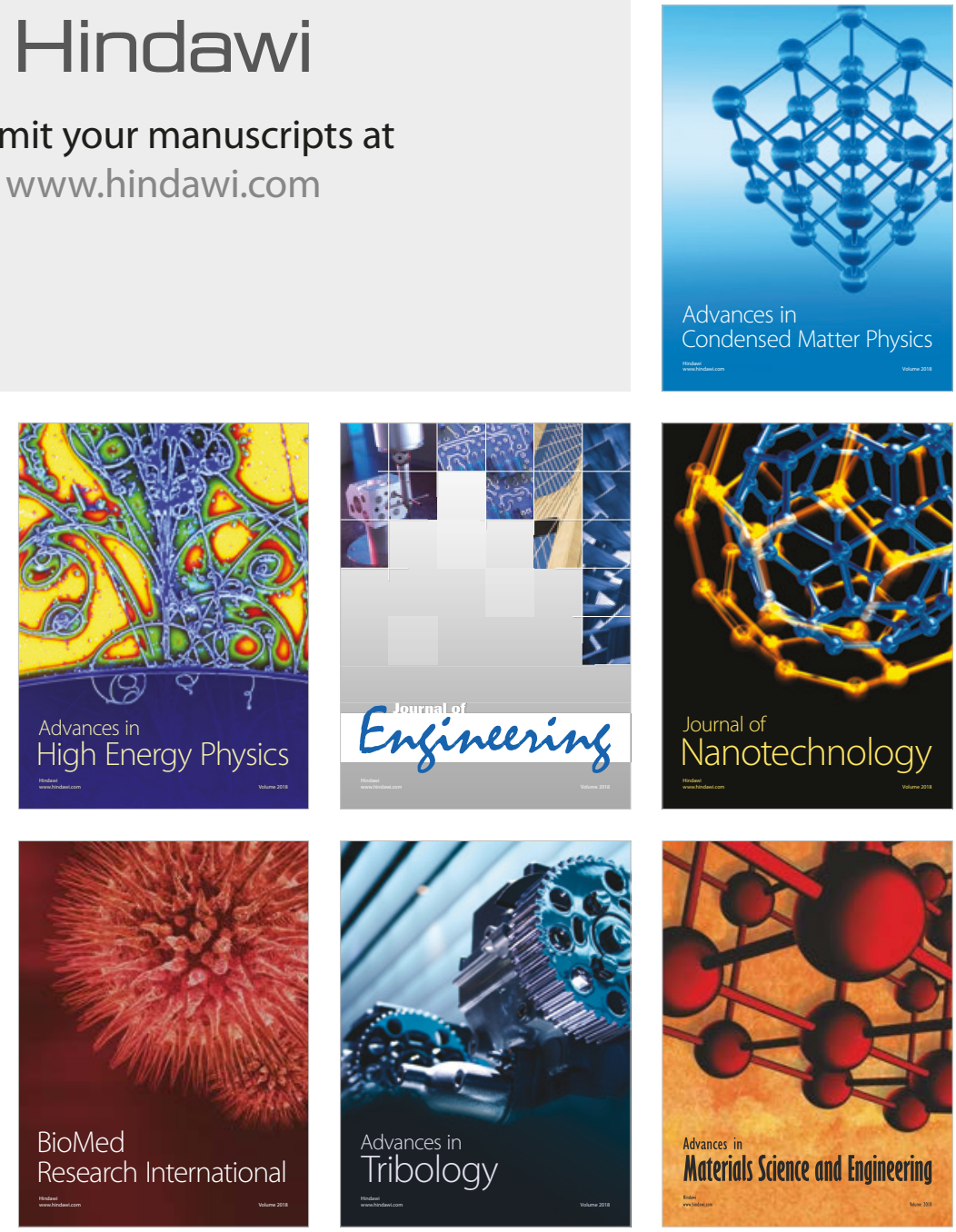